\title{
MULTI-MODAL DIGITAL DOCUMENTATION AND VISUALIZATION OF THE UNESCO PAINTED CHURCHES IN TROODOS (CYPRUS)
}

\author{
D. Abate ${ }^{1}$, M. Faka ${ }^{1}$ K. Toumbas ${ }^{1}$, N. Bakirtzis ${ }^{1}$, W. Mitchell ${ }^{2}$, K. Colls ${ }^{2}$, C. Sturdy-Colls ${ }^{2}$ \\ ${ }^{1}$ The Cyprus Institute, Science and Technology in Archaeology and Culture Research Center (STARC), Andreas Pittas Art \\ Characterization Laboratories (APAC Labs), Cyprus \\ ${ }^{2}$ Staffordshire University, Centre of Archaeology, United Kingdom
}

\section{Commission II}

KEY WORDS: Terrestrial Laser Scanning, Terrestrial Photogrammetry, Aerial Photogrammetry, Ground Penetrating Radar, Web Visualization

\begin{abstract}
:
In 1985, the World Heritage Committee inscribed the site "Painted Churches in the Troodos Region" of the Republic of Cyprus on the UNESCO World Heritage List. The latter included nine Byzantine and Post Byzantine Churches to which a tenth church was added in 2001. In the framework of the IH-AT project, all the churches and the premises in their proximities were analysed using a wide array of non-destructive digital methodologies coupled with more traditional art-historical studies. Image- and Range-based techniques were used to document all the morphological features of the buildings with the final goal of understanding their humble architecture. Additionally, a Ground Penetrating Radar (GPR) was performed to investigate the presence of buried structures that, according to historical sources, were once surrounding the religious sites.

For the exploitation and visualization of the extensive database by the scientific community and the public at large, a web portal comprised of reliable and efficient technology-ready tools have been developed.

The proposed methodology was implemented to provide new insights on the churches' architectural features; confirm the presence or absence of buried remains of archaeological interest; and help heritage professionals, with lack or minimal programming skills, to customize online visualizations of $3 \mathrm{D}$ interactive models.
\end{abstract}

\section{INTRODUCTION}

With dates ranging from the eleventh through the sixteenth century, the ten chapels included in the UNESCO monument preserve rich wall-painting decorative programs which stand out for their high quality and style (Stylianou and Stylianou, 1997, Hein et al., 1998). The architecture of these churches echoes evolutions in Middle Byzantine architecture but also local and regional responses to the religious needs of patrons and rural societies (Figure 1). Using local building materials and featuring stone and brick masonry, early examples were built following standard Byzantine architectural typologies such as cruciform and cross-in-square buildings topped with beautiful domes, lately covered by elaborated wooden roofs (Ćurčić, 2000; Ćurčić, 2018).

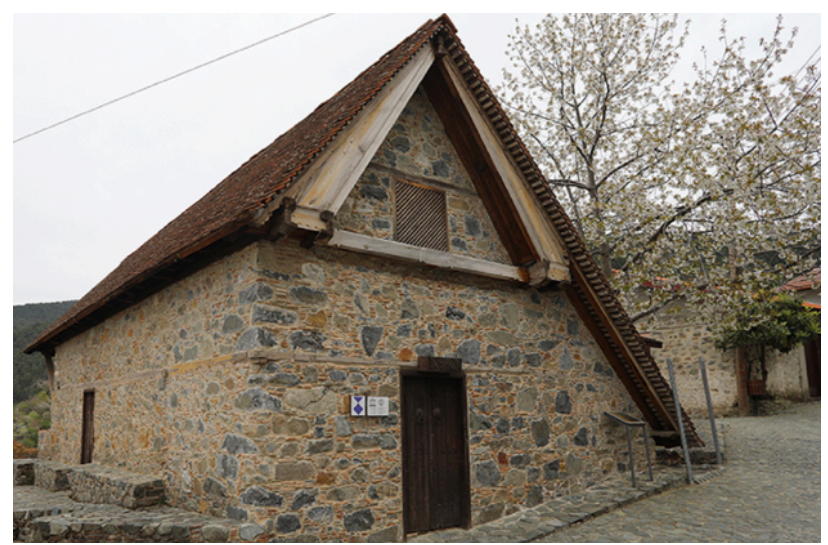

Figure 1. Archangelos Michail, Pedoulas, exterior.

In addition to the study of the art of these chapels, little is known about their original monastic contexts as most of these church buildings formed part of much larger monastery complexes. The lack of systematic archaeological work around these rural churches has denied a better understanding of the complex histories of the now lost Byzantine monasteries.

Through the IH-AT multimodal documentation approach (Section 3), a wide array of digital-born data was collected, processed and combined to allow an in-depth understanding of these monuments, linking in the same virtual environment, above and below ground structures.

An accessible web portal was developed for the visualization and scientific analysis of 2D and 3D data (Section 4). New tools were ad-hoc implemented, facilitating the understanding of hidden and today lost features (Section 4.1, 4.2, 4.3). Additionally, a userfriendly web application was developed with the final goal of assisting non-technical users to deploy 2D and 3D data online (Section 4.4).

\section{RELATED WORKS}

\subsection{Multi-Modal Digital Documentation}

During the last two decades, digital technologies have revolutionised the way heritage assets are studied.

The digital documentation of structures and excavation became indeed a standard practice in archaeology (Bariami, et al., 2012). Multi-resolution approaches and the integration of different modelling technologies can indeed provide the best results for integrating landscape, structures, stratigraphic excavation and finds. To date, several projects have been implemented that apply multidisciplinary approaches which exploit non-contact and nondestructive digital technologies for the documentation of standing structures or underground features.

A multi-resolution and multi-sensor approach has been developed by Guidi et al., (2008 and 2009) for the accurate and detailed 3D modelling of the entire Roman Forum in Pompei. 
Active and passive sensors were used for the digital documentation of the archaeological site trying to fulfil all the surveying and archaeological needs whilst exploring all of the intrinsic potentialities of the 3D modelling techniques.

Remondino et al., (2009) presented a reality-based project, exploiting multi-resolution and multi-source documentation for the digital reconstruction of a part Maya archaeological site of Copán, Honduras. The final objectives were to provide digital 3D models for research and public education purposes.

The use of terrestrial laser scanning (TLS) and close-range photogrammetry are presented in Lerma et al., (2010). The authors present the production of accurate and high-resolution 3D models of a cave with engravings dating back to the Upper Palaeolithic era in Spain.

A further multiple data source documentation method was implemented by Fassi et al., (2011) to survey the main spire of Milan Cathedral. The authors describe the survey workflow and processing steps, focusing on problems and key choices.

In Fiorillo et al., (2013), the integration of different 3D recording techniques and instruments to survey the archaeological area of Paestum (Italy) were described.

The data fusion concept so far presented in the research community are reviewed in Ramos and Remondino (2015). The authors aimed to provide an understanding of the actual methods of data fusion and clarify some open research issues.

In Nocerino et al., (2017) 3D surveying and modelling techniques have been exploited to produce 3D digital models of structures and objects, along with virtual tours, communication material and a WebGIS of the area. All the products are available on the web for valorisation, educational and communication purposes.

An innovative and interdisciplinary approach was adopted for the modelling of the Holy Aedicule of the Church of the Holy Sepulchre in Jerusalem (Moropolou et al., 2017). It utilized data from several sources including architectural drawing, 3D modelling techniques, and ground-penetrating radar (GPR).

The Treblinka (Poland) concentration camp was studied using 3D technologies, geophysics and web visualization, creating a digital interactive platform. This project proposed a pyramidal multilevel and multi-sensor approach (Abate and Sturdy Colls, 2018).

\subsection{D Web-Visualization}

The exploitation of real-time web resources by the cultural heritage domain mainly comprises the publication of highresolution 3D models and associated metadata online, in form of meshes and point clouds. Reality-based models, produced by terrestrial laser scanning and photogrammetry, are usually the main 3D digitization datasets that need to be handled. The latter requires the adoption of multi-resolution representations and performant data transfer formats.

The cultural heritage community is keen to use tools developed in other scientific domains such as games design, programming, or animation (Unity Technologies, 2005; Epic Games, 2014).

Different approaches have been proposed in the literature for the online visualization of large 3D datasets. Previous research undertaken by the scientific community focused on the rendering and visualization, in real-time and possibly via the web, of large 3D models (Gobetti, et al., 2006; Yoon et al., 2008; Di Benedetto et al., 2009; Potenziani et al., 2011). Generally, a hierarchical and local representation of geometry and texture is employed (LOD approach). Schulz (2016) introduced the open-source WebGLbased Potree viewer, a point-based rendering solution developed explicitly for visualizing large point clouds using standard webbased technologies. It is capable of efficiently providing a responsible interactive viewer that only requires a standard web browser (WebGL enabled), freeing the user from any configuration issue or specific software.

\section{DATA COLLECTION METHODOLOGY}

The Multi-Modal Digital Documentation of the UNESCO Painted Churches in Troodos (Cyprus) was performed exploiting several non-destructive digital techniques.

All ten UNESCO sites were digitized using range- and imagebased techniques, both terrestrial and aerial, with the final goals of reconstructing the morphological features and primary construction techniques.

A preliminary desk-based assessment using maps, historical photos, current photos, and drawings was realized to maximize the efforts and efficiently plan each fieldwork campaign (Figure 2).

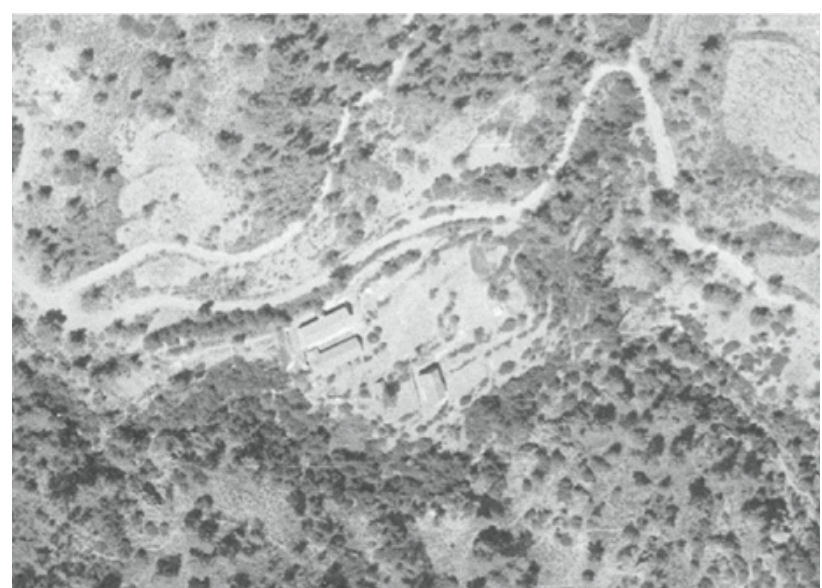

Figure 2. Panagia tou Araka, Lagoudhera. 1963, historical aerial picture, Department of Land and Survey of Cyprus.

\subsection{Terrestrial Laser Scanning}

A Terrestrial Laser Scanning (TLS) survey was performed using a phase shift laser scanner with a certified accuracy of $5 \mathrm{~mm}$ at 5 $\mathrm{m}$. Although the misleading simple appearance of the churches, each structure presented specific challenges which had to be faced to obtain a complete 3D model, without any occlusions generated by movable objects or the structures themselves. Some churches were indeed characterized by very complex external and internal spatial organization requiring very demanding setups including an extendable tripod which allowed access to hard to reach locations otherwise impossible to digitize. (Figure 3 and 4).

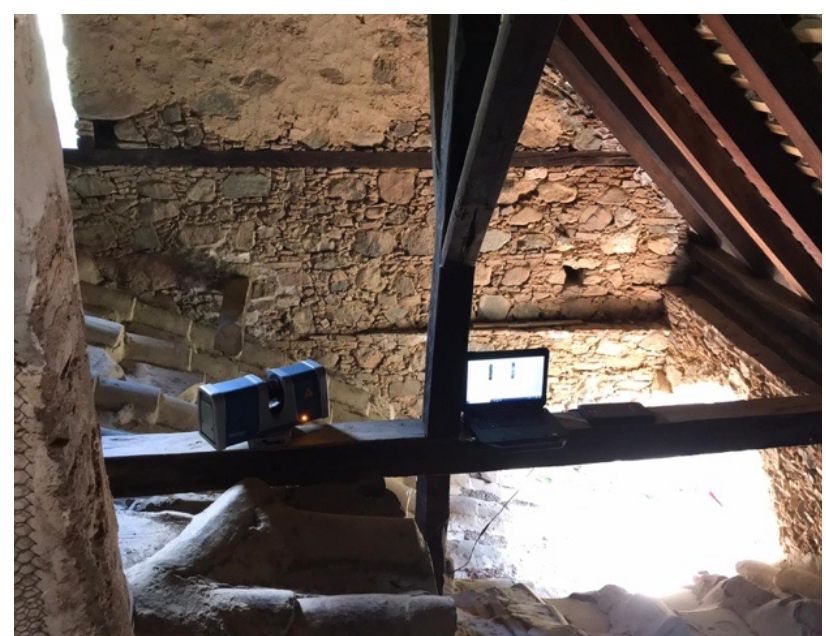

Figure 3. Agios Nikolaos tis Stegis, Kakopetria, TLS 3D survey, inner roof. 


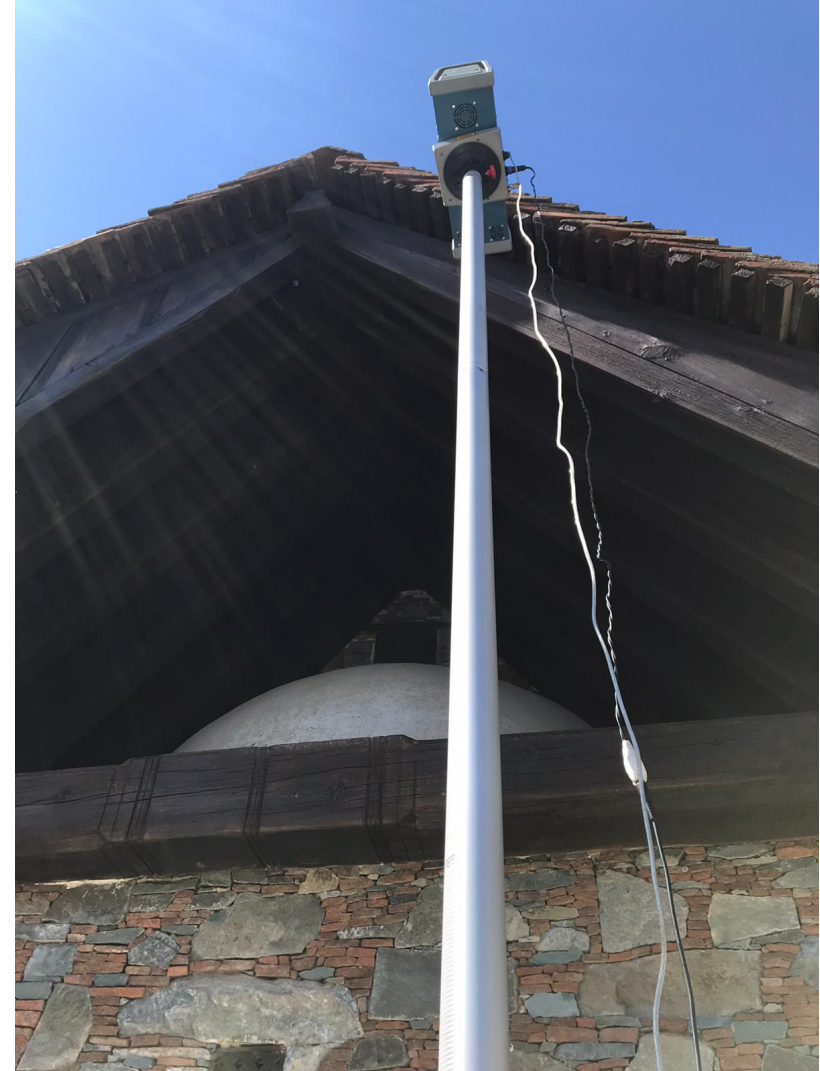

Figure 4. Metamorphosis tou Sotiros, Palaichori, TLS 3D survey, exterior.

Table I summarizes the range maps collected per site in terms of RAW data, converted files and final merged 3D point clouds. The number of range maps was determined either by the dimension of the churches or by their complexity.

\begin{tabular}{|c|c|c|c|}
\hline Site & C3D & PTX & PLY \\
\hline $\begin{array}{c}\text { Stavros tou } \\
\text { Agiasmati }\end{array}$ & 118 & 118 & 3 \\
\hline Panagia tis Podithou & 91 & 91 & 3 \\
\hline $\begin{array}{c}\text { Panagia } \\
\text { Phorviotissa } \\
\text { (Asinou) }\end{array}$ & 92 & 92 & 3 \\
\hline $\begin{array}{c}\text { Agios Nikolaos tis } \\
\text { Stegis } \\
\end{array}$ & 148 & 148 & 3 \\
\hline Panagia tou Araka & 156 & 156 & 3 \\
\hline $\begin{array}{c}\text { Panagia tou } \\
\text { Moutoulla }\end{array}$ & 42 & 42 & 3 \\
\hline $\begin{array}{c}\text { Archangelos } \\
\text { Michail }\end{array}$ & 79 & 79 & 3 \\
\hline $\begin{array}{l}\text { Metamorphosis tou } \\
\text { Sotiros }\end{array}$ & 62 & 62 & 3 \\
\hline Timios Stavros & 71 & 71 & 2 \\
\hline $\begin{array}{l}\text { Agios Ioannis } \\
\text { Lambadistis }\end{array}$ & 292 & 292 & 3 \\
\hline
\end{tabular}

After the application of the traditional post-processing pipeline for range-based data (alignment, filtering, merging), each site was subdivided into several sub-units (i.e., naos, roof, ambulatory, narthex, etc.). The resulting point clouds were finally integrated into a single geographic reference system (WGS84 UTM $36 \mathrm{~N})$. Each model was finally exported in an average of 5 mm resolution (Figure 5).

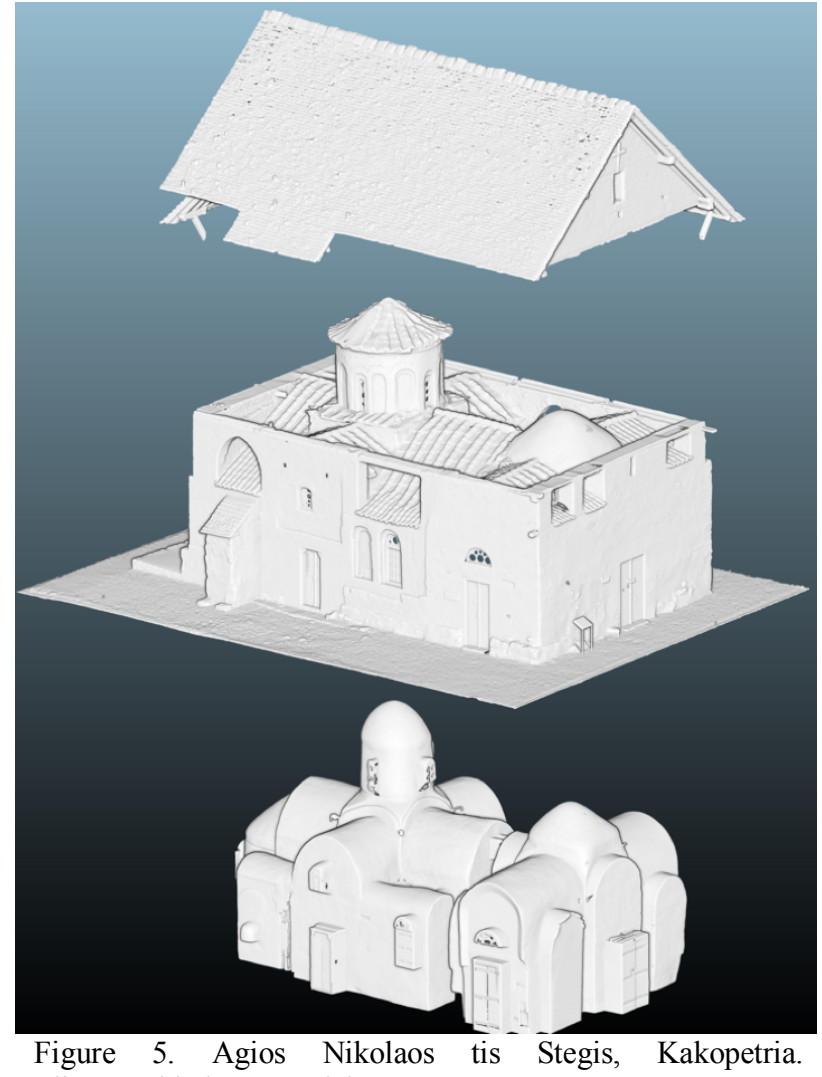

'disassembled' 3D model.

Although primary efforts to digitize each structure in their entirety was attempted, in some cases gaps in the data remained due to non-movable objects or the impossibility of reaching specific areas. This was mainly the case in overhead spaces. In order to produce complete models, manual modelling was necessary. Art-Historical studies and images were used as sources of information ( $\Lambda \nu \mu \pi о \nu \rho \eta ́-K o \zeta \alpha ́ \alpha o v, 2005$.), to realize a philological reconstruction of the missing parts (Figure 6 and 7).

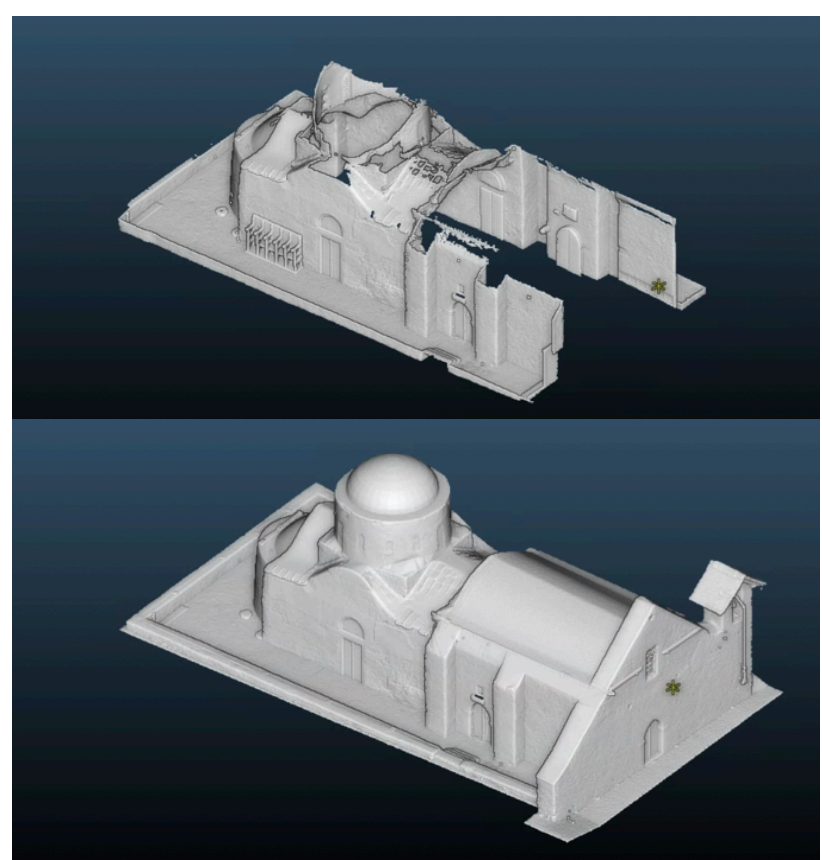

Figure 6. Panagia tou Araka, Lagoudhera, ambulatory before (top) and after (bottom) the virtual reconstruction. 


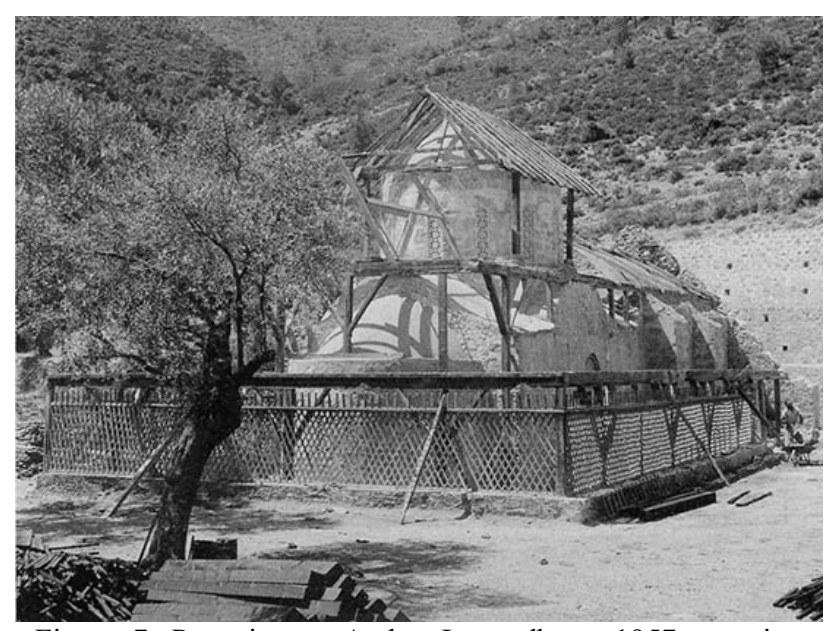

Figure 7. Panagia tou Araka, Lagoudhera, 1957, exterior, Department of Antiquities of Cyprus.

\subsection{Image-based 3D modelling}

The need for image-based surveys was twofold: terrestrial photogrammetry was used to map the colours of the interior and the exterior of the churches since the TLS used for the architectural survey did not provide any RGB colour information; aerial photogrammetry instead was used to reconstruct the roof systems of those sites where, due to the height of the churches, the TLS was ineffective.

\subsubsection{Terrestrial Photogrammetry}

For each church, an image camera network was created using either a DSLR camera equipped with a $20 \mathrm{~mm}$ prime lens or a $360^{\circ}$ camera. For the latter, starting from the pre-processed panoramas, a bundle adjustment with a spherical camera model was employed. Panoramic imaging was mainly used when the extension of the site and the time available to perform the data collection were fixed.

The photogrammetric pipeline was applied up to the image alignment stage. Coordinates extracted from the TLS point clouds were used to scale the models and place the two models in the same spatial reference systems. RGB colours were then projected on the imported TLS 3D point clouds (Figure 8 and 9).

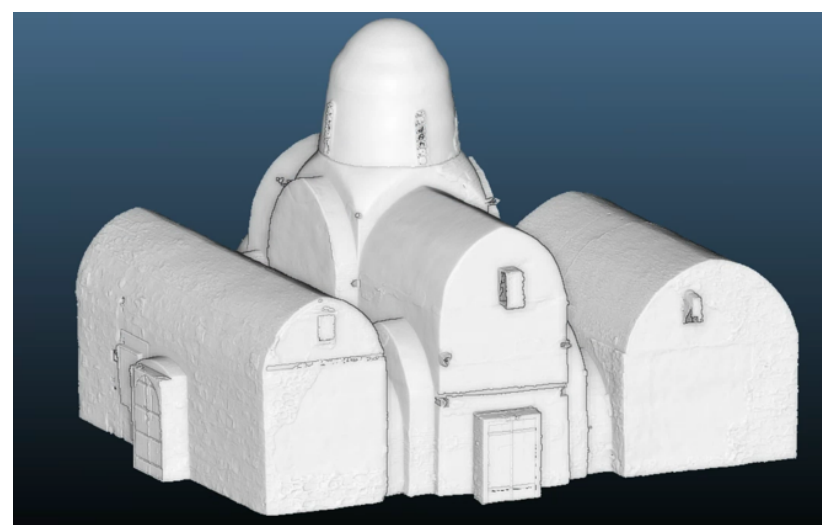

Figure 8. Timios Stavros, Pelendri, interior, shaded model.

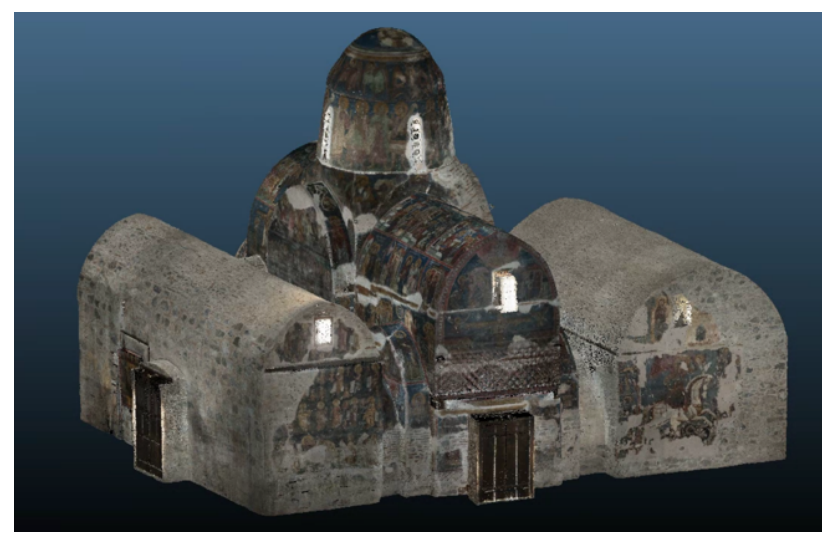

Figure 9. Timios Stavros, Pelendri, interior, RGB model.

\subsubsection{Aerial Photogrammetry}

In order to avoid large gaps in the roofing system, and to create a Digital Elevation Model (DEM) of the church premises deemed suitable for the GPR surveys (section 3.3), an aerial image-based survey was completed using a UAV platform. The flight plan was implemented to achieve a forward and lateral image overlap of $\sim 80 \%$, and an average Ground Sampling Distance (GSD) of $\sim 2$ $\mathrm{cm}$. All RAW data were initially pre-processed to enhance the images' features. Unlike the terrestrial photogrammetric survey, the aerial one was used to create geometric features. Accordingly, the typical photogrammetric workflow, consisting of three main steps, (image correspondences detection, bundle adjustment and dense image matching using the first-level image pyramid) was used (Figure 10).

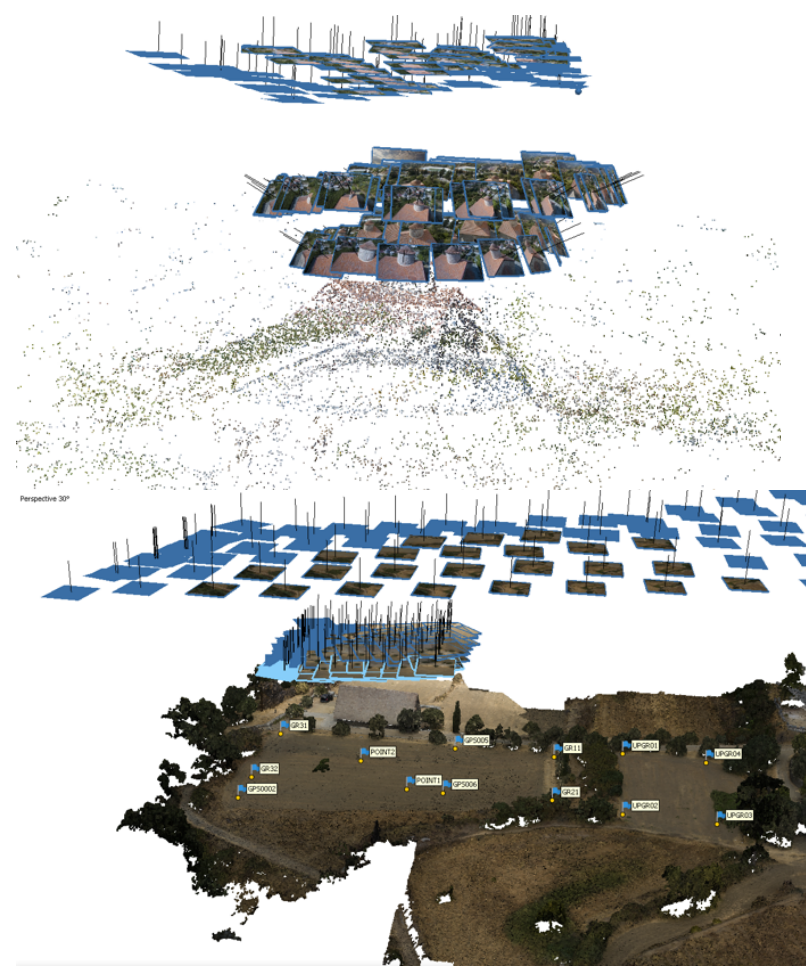

Figure 10. Timios Stavros, Pelendri, aerial surveys, sparse point cloud (top); Panagia tis Podithou, Galata, dense point cloud (bottom). 
All the generated models were referenced in the WGS84 UTM $36 \mathrm{~N}$ coordinate system and merged with the TLS data. In order to reduce the residual error, a refinement of the registration between the 3D data was performed using state-of-the-art algorithms (e.g. ICP - Iterative Closest Point). The accuracy of this integration was metrically evaluated with different approaches, including global and local comparisons performed.

\subsection{Ground Penetrating Radar}

From the list of ten UNESCO churches, four were built as private chapels and are today embedded in the urban fabric of the villages in which they reside. The remaining six were monasteries, five of which were identified as suitable for Ground Penetrating Radar (GPR) surveys (Grasmueck, et al., 2015; Conyers, 2015; Utsi, 2017, Mitchell et al, 2022).

Each of these sites (Agios Nikolaos tis Stegis, Panagia Phorviotissa (Asinou), Panagia tou Araka, Panagia tis Podithou and Stavros tou Agiasmati) was chosen for its potential to have preserved underground architectural remains from buildings belonging to the original monasteries. These remains were expected to be either former monastic buildings (including former crypts or vaults) or burials, being that these were monastic grounds. The remaining site, Agios Ioannis Lambadistis, was excluded from the geophysical survey since the whole monastery is still preserved and in use.

A number of surfaces and subsurface features were observed during the post-processing of the GPR data and the surveys provided new insights into the preservation and destructive processes that have occurred at each site in the decades since the redevelopment of each monastic complex.

The most noteworthy geophysical results came from two of the five monastery sites surveyed, specifically the Panagia Phorviotissa (Asinou) near Nikitari and the Panagia tou Araka near Lagoudhera (Figure 11). At Panagia Phorviotissa (Asinou), three features are likely to represent new buried structural features directly associated with the surviving church structure. At Panagia tou Araka, the anomalies identified in the data possibly represent buried walls and structural remains. Targeted confirmatory excavations are recommended at these sites as buried structural remains are highly likely to exist.

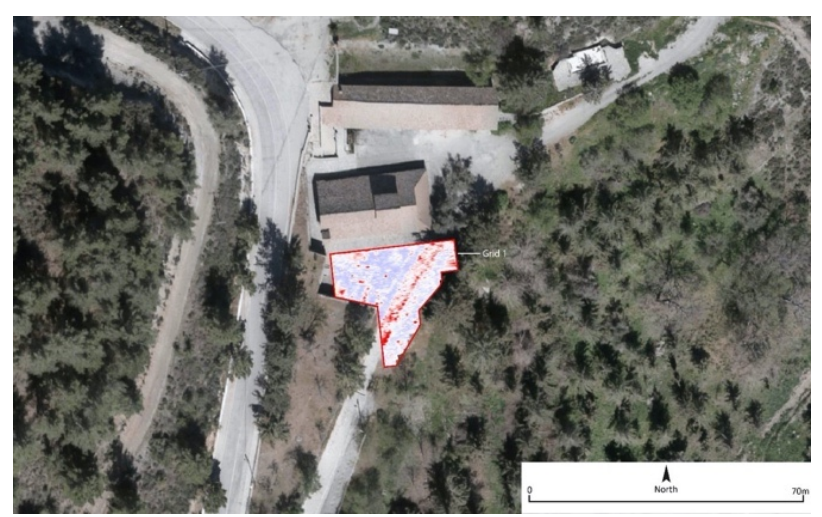

Figure 11. Panagia tou Araka, Lagoudhera, GPR survey.

\section{VISUALIZATION FRAMEWORK}

Through the IH-AT platform architecture (http://ihat.cyi.ac.cy), all the models are available online via the Potree viewer. The standard Potree Libraries (v1.7.2) were extended to create several interactive new tools. Concerning the latter, a region of the rendered viewer is overwritten with custom HTML and ThreeJS JavaScript that loads after the Potree Viewer interface initialization. The tools are developed using the VueJS frontend framework and are bundled using Webpack.

The platform employs a User Management system that can identify Users using a set of username/password credentials.

Non-authenticated users have read-only access mode without the ability to modify the settings or configuration (Figure 12).

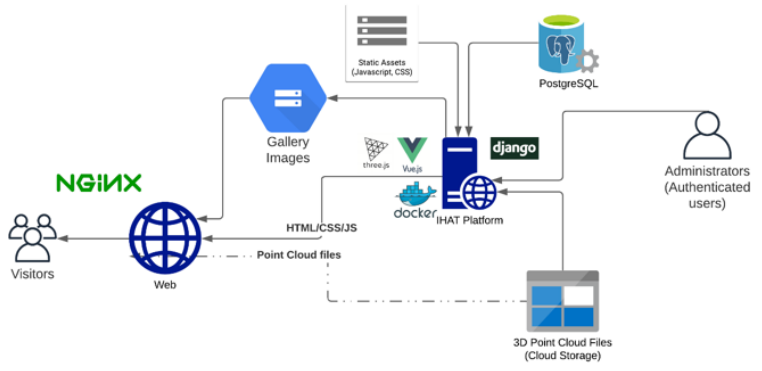

Figure 12. IH-AT system architecture.

\subsection{IH-AT Platform Back-End}

An Admin panel was created and tailored to allow user-friendly customization of the front-end interface (Figure 13).

The web application was developed using the Django Web Development Framework, written in Python Programming Language. Once uploaded on the web server, each Point Cloud were bundled together using a 'Visualization' concept. The latter is assigned a unique ID, and a hyperlink is generated. It holds an entry in a database that stores the following information:

- list of point-cloud URLs (links that point to the publicly available 3D models),

- $\quad$ set of configuration parameters for the Potree Viewer (i.e., number of points, illumination parameters, background. etc.),

- set of metadata that describes the visualization (title, subtitle, description, etc.),

- reference to the administrator user of the 'Visualization', enabled to modify the parameters.

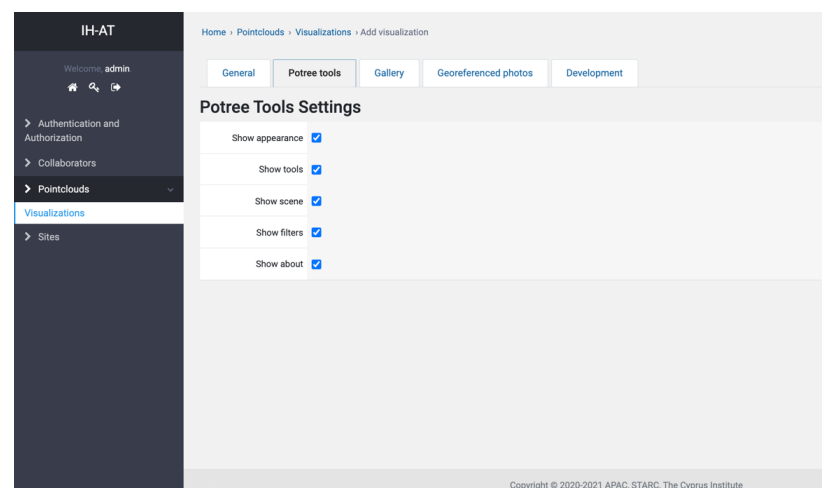

Figure 13. IH-AT platform back-end.

\subsection{Explosion Tool}

Each 3D model of the UNESCO churches in Troodos available on the IH-AT platform comprises several sub-units (i.e., naos, roof, ambulatory, narthex, etc.). Each building is formed from a minimum of two point clouds. However, when visualized as a simple block, the inner structure of each building is not always explicit.

In order to facilitate an understanding of the architectural design of each church, an interactive 3D model explosion tool has been developed (Figure 14). In administration mode, during the 
viewer's parameters' setup, it is possible to define the axis toward which every single unit (point cloud) will move in the 3D space and the speed of the explosion effect. The different objects are hence disassembled, and the construction features are highlighted. If enabled, a slider becomes available to the viewer. The interaction happens in real-time. By using the slider function and dragging across, each part gets further away from the centre $(0,0,0)$ of the scene according to the movement configured.

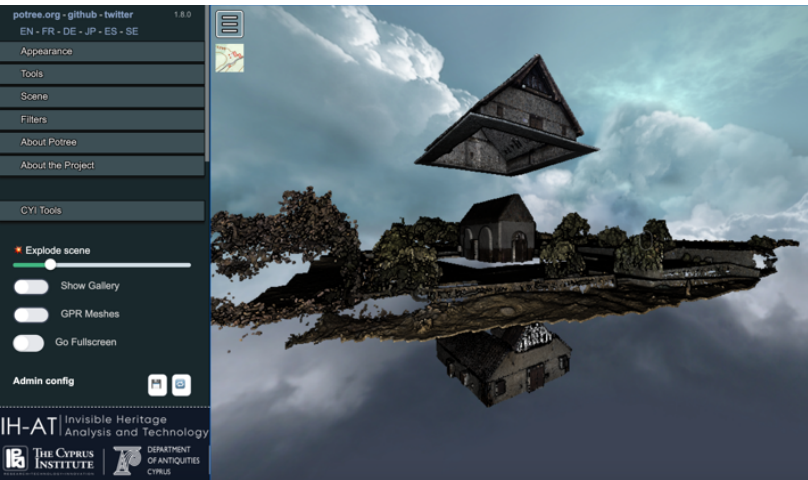

Figure 14. Panagia tis Podithou, Galata, explosion tool.

\subsection{Image Gallery}

Besides the 3D models of each church, an extensive repository of $2 \mathrm{D}$ images has been created during the IH-AT project, including contemporary and historical photographs and sketches. This database resource is also available within the same 3D web environment. The collection of images has been uploaded through the administrator panel to generate an image gallery enriching the $3 \mathrm{D}$ visualization. A sidebar with images stacked and described by title was designed and integrated into the Potree viewer. With the final goal to provide an immersive user experience, the 3D model of each church has been aligned, resembling the perspective, and the zoom level of the historical picture. When the alignment is achieved, the model positioning parameters are stored accordingly. Each image is then rendered on top of the 3D scene. A slider has been implemented to change the opacity, allowing the viewer to visualize both the image and the 3D scene simultaneously (Figure 15).

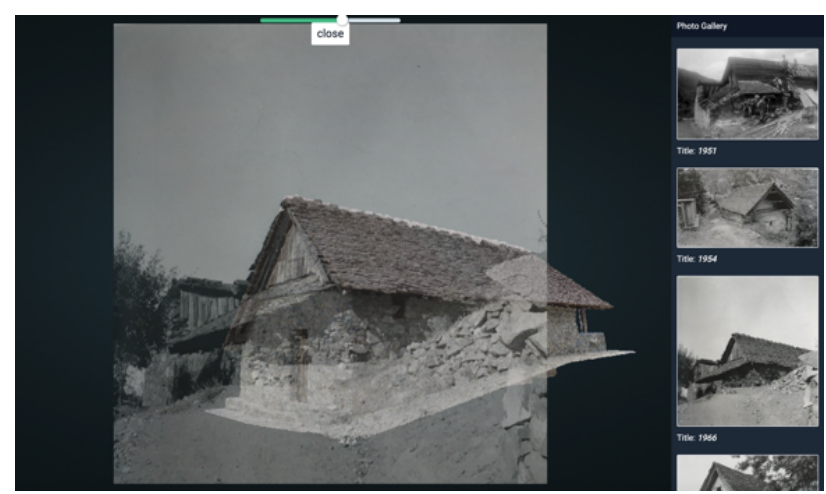

Figure 15. Panagia tou Moutoulla, Moutoullas, image gallery.

\subsection{GPR Data Visualization}

The Image Gallery described above has been conceived to visualize $2 \mathrm{D}$ static images exclusively, without embedded geospatial references. The GPR data instead is based on realworld coordinates. These $2 \mathrm{D}$ images have been rendered into the
3D space as flat 3D objects. This approach allows orienting them into the scene having the same behaviour as the $3 \mathrm{D}$ point clouds (Figure 16). Each image includes coordinate data comprising of easting, northing, and elevation parameters. The administration panel allows the user to link the rectangular image known corners with their GPS points, translating them to the same position matrix of the displayed 3D model. A 3D mesh is then created with a minimal thickness to appear as a flat surface and the GPR image is automatically applied as a texture. Where multiple GPR timeslices are available for different depths, several layers are created and available in the customised Potree sidebar.

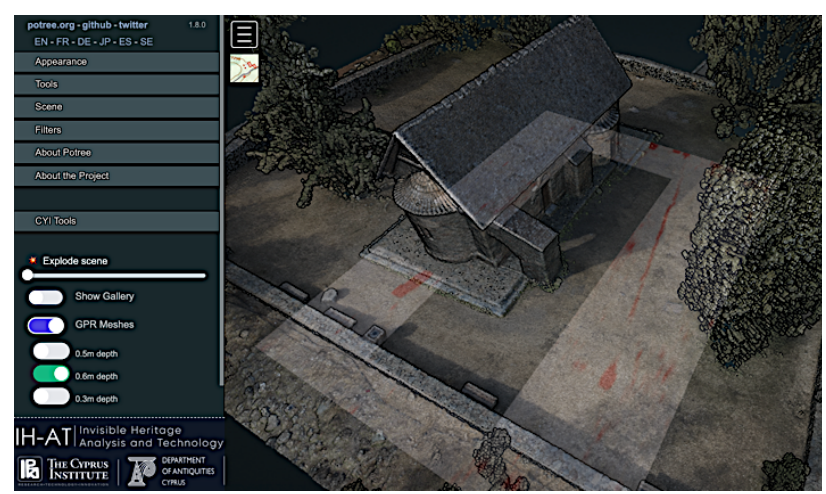

Figure 16. Panagia Phorviotissa (Asinou), Nikitari, 3D point cloud and GPR data $(-0.6 \mathrm{~m})$ displaying underground features.

\section{CONCLUSIONS}

This paper describes the holistic approach developed for the study and the analysis of a cluster of UNESCO listed churches in the Troodos area. The main aims were to preserve by way of record the existing structural remains and to identify lost features. This pilot application will help to inform further research and conservation projects at the specific UNESCO churches, ranging from (but not limited to) architectural studies, archaeological excavations, to new art-historic interpretation (Figure 17).

The multimodal reality-based 3D modelling strategy allowed us to collect an extensive morphological database of all the standing structures. It will represent the background for multitemporal monitoring of the churches' conservation conditions.

The Ground Penetrating Radar survey allowed us to enhance both the archaeological knowledge of the sites and our understanding of the use of GPR within the Troodos region.

A large amount of digital-born data was finally fused in the framework of the IH-AT web platform, conceived as an interactive database from which information and data can be visualized, analysed, and extracted.

Although based on the successful and established Potree libraries, the IH-AT platform features a series of new tools for visualizing $2 \mathrm{D}$ and 3D data through standard WebGL browsers. All the code will be licensed under a Creative Commons Attribution Non-Commercial 4.0 International License.

\section{FUNDING}

This research was funded by the project EXCELLENCE/0918/0144, co-financed by the European Regional Development Fund and the Republic of Cyprus through the Research and Innovation Foundation. 


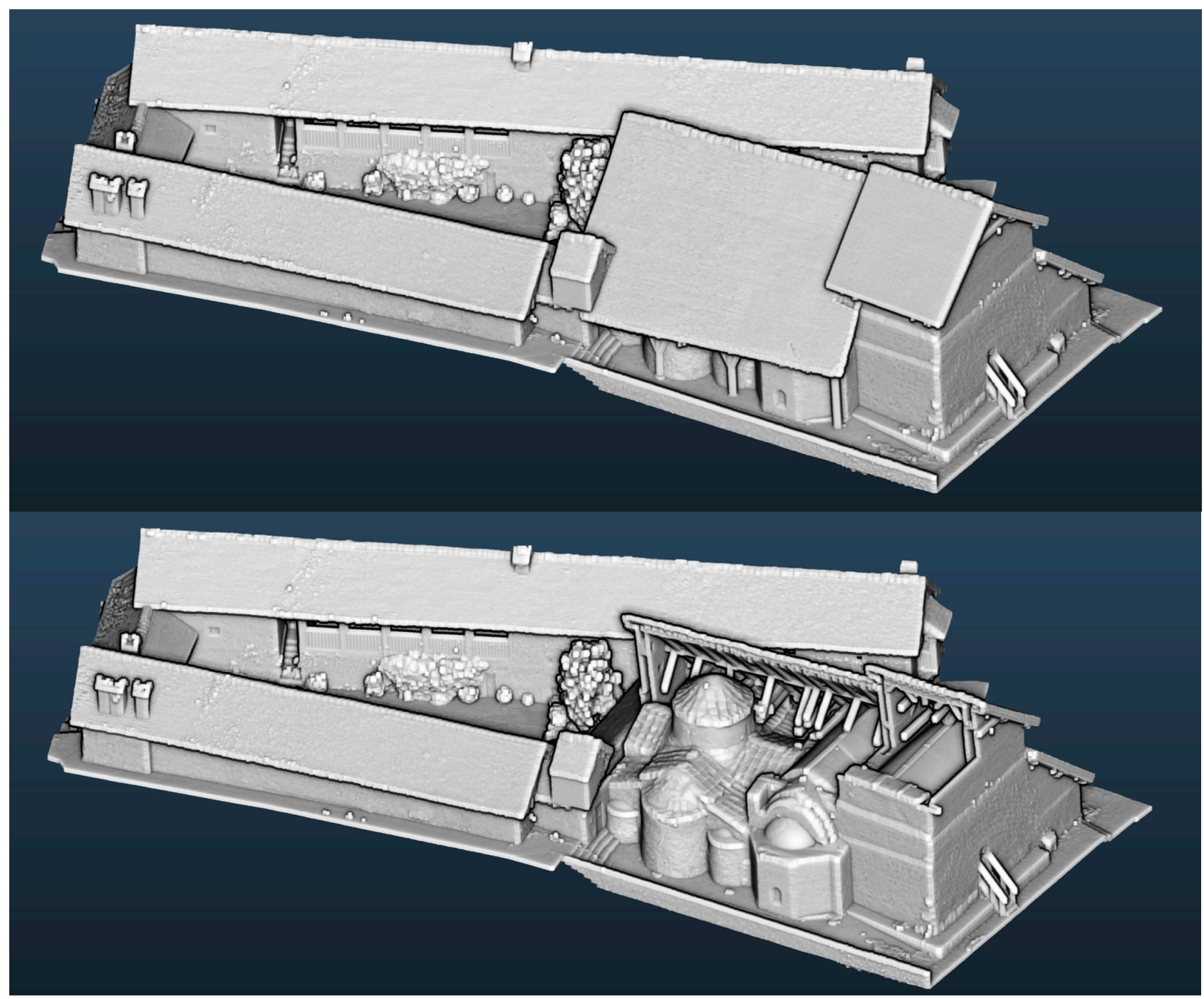

Figure 17. Agios Ioannis Lambadistis, Kalopanayotis, exterior (top), exterior with a section of the roof (bottom).

\section{ACKNOWLEDGEMENTS}

The authors wish to thank the Department of Antiquities of Cyprus, and in particular its director Dr. Marina SolomidouIeronymidou, for the authorisation to conduct the fieldwork. Additionally, the IH-AT team acknowledges the support of the Bishopric of Morphou and the Archbishopric of Cyprus for the support provided on-site during the data collection.

The Department of Land and Survey of Cyprus is acknowledged for granting the use of aerial historical images.

A special mention goes to Mr Haycock and Ms Copley of Staffordshire University for the GPR data collection survey, to Ms Papacharalambous of the Cyprus Institute for contributing to research on the history and the art of the Troodos churches, and to Ms Papageorgiou and Ms Agapiou of the Cyprus Institute for the data collection and database ingestion.

\section{REFERENCES}

Abate, D. and Sturdy-Colls, C., 2018. A multi-level and multisensor documentation approach of the Treblinka extermination and labor camps. Journal of Cultural Heritage, 34, 129-135.

Bariami, G., Faka, M., Georgopoulos, A., Ioannides, M. and Skarlatos, D., 2012. Documenting a Unesco WH Site in Cyprus with complementary techniques. International Journal of Heritage in the Digital Era, 1(1_suppl), pp.27-32.
Conyers, L.B., 2015. Ground-Penetrating Radar for Archaeology. In Geophysical Methods for Archaeology No. 4, 3rd ed. AltaMira Press, Lanham, MD, USA, Volume 23, pp. 7172. https://doi.org/10.1002/arp.1518.

Ćurčić, S., 2000. Middle Byzantine Architecture on Cyprus: Provincial or Regional? Bank of Cyprus Cultural Foundation: Nicosia, Cyprus.

Ćurčić, S., 2018. Architecture of Panagia Arakiotissa, Lagoudera, in Papageorghiou, A., Bakirtzis, C., Hadjichristodoulou, C. eds. The Church of Panagia tou Arakos; Leventis Foundation and Bank of Cyprus Cultural Foundation Nicosia: Nicosia, Cyprus, pp. 19-26.

Di Benedetto, M., Cignoni, P., Ganovelli, F., Gobbetti, E., Marton, F., Scopigno, R., 2009. Interactive remote exploration of massive cityscapes. pp. 9-16. doi:10.2312/VAST/VAST09/009016. 2 .

Epic Games. Unreal Engine, 2014 https://www.unrealengine.com (last accessed 24/01/2022).

Fassi, F., Achille, C., Fregonese, L., 2011. Surveying and modeling the main spire of Milan Cathedral using multiple data sources. Photogrammetric Record, 26, 462-487. 
Fiorillo, F., Fernandez-Palacios, B. J., Remondino, F., Barba, S., 2013. 3D Surveying and modelling of the Archaeological Area of Paestum, Italy. In: Virtual Archaeology Review, 4(8), pp. 5560 .

Gobbetti E., Marton F., Cignoni P., Di Benedetto M., Ganovelli F., 2006. C-bdam - compressed batched dynamic adaptive meshes for terrain rendering. Computer Graphics Forum 25, 333 -342. doi:10.1111/j.1467-8659.2006.00952.x. 2.

Grasmueck, M., Weger, R., Horstmeyer, H., 2005. Fullresolution 3D GPR imaging. Geographycs, 70, 12-26. https://doi.org/10.1190/1.1852780.

Guidi, G., Remondino, F., Russo, M., Menna, F., Rizzi, A., 2008. 3D modeling of large and complex site using multi-sensor integration and multi-resolution data, in: Proc. 9th Int. Symposium on virtual reality, archaeology and cultural heritage (VAST), Braga, Portugal, pp. 85-92.

Guidi, G., Remondino, F., Russo, M., Menna, F., Rizzi, A., Ercoli, S., 2009. A multi-resolution methodology for the 3D modeling of large and complex archaeological areas, Int. J. Architect. Comput. 7 (1) 39-55.

Hein, E., Jakovljevic, A., Kleidt, B., 1998. Cyprus: Byzantine Churches and Monasteries, Mosaics and Frescoes; Melina: Ratingen, Germany.

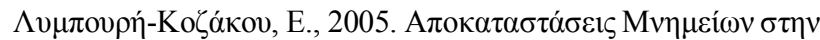

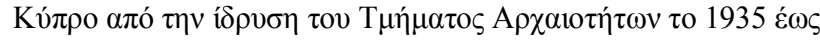
$\tau$, pp. 81-83.

Lerma, J.L., Navarro, S., Cabrelles, M., Villaverde, V., 2010 Terrestrial laser scanning and close-range photogrammetry for 3D archaeological documentation: the Upper Palaeolithic Cave of Parpallo as a case study. Journal of Archaeological Science, 37, 499-507.

Mitchell, W.L., Abate, D., Colls, K.S., Faka, M., Sturdy Colls, C. Bakirtzis, N., 2022 Ground Penetrating Radar Survey of the UNESCO Painted Churches in the Troodos Region (Cyprus). Heritage, 5, 260-285. https://doi.org/10.3390/ heritage5010014.

Moropoulou, A., Georgopoulos, A., Korres, M., Bakolas, A., Labropoulos, K., Agrafiotis, P., Delegou, E.T., Moundoulas, P., Apostolopoulou, M., Lambrou, E., Pantazis, G., Kotoula, L., Papadaki, A.I., \& Alexakis, E., 2017. Five-Dimensional (5D) Modelling of the Holy Aedicule of the Church of the Holy Sepulchre Through an Innovative and Interdisciplinary Approach. Mixed Reality and Gamification for Cultural Heritage.

Nocerino, E., Menna, F., Morabito, D., Remondino, F., Toschi, I., Abate, D., Ebolese, D., Farella, E., Fiorillo, F., Minto, S., Rodríguez-Gonzálvez, p., Slongo, C., Spera, M.G., 2017. The Vast Project: Valorisation of History and Landscape for Promoting the Memory of WWI. ISPRS Ann. Photogramm. Remote Sens. Spat. Inf. Sci., IV-2/W2, 179-186.

Potenziani, M., Callieri, M., Dellepiane, M., Corsini, M., Ponchio, F., Scopigno, R., 2015. 3DHOP: 3D heritage online presenter. Computer Graphics, 52, 129-141.

Ramos, M., Remondino, F., 2015. Data fusion in cultural heritage - A Review. ISPRS archives of the photogrammetry, Remote
Sens. Spat. Info. Sci. XL-5/W7, 359-363 (25th CIPA Symposium, Taipei, Taiwan).

Remondino, F., Gruen, A., von Schwerin, J., Eisenbeiss, H., Rizzi, A., Sauerbier, M., Richards-Rissetto, H., 2009. Multisensors 3D documentation of the Maya site of Copan, in: Proc. of 22nd CIPA Symposium, Kyoto, Japan.

Schütz, M., 2016. Potree: Rendering Large Point Clouds in Web Browsers; Technische Universität Wien: Wien, Austria.

Stylianou, A. and Stylianou, J., 1997. The Painted Churches of Cyprus, Treasures of Byzantine art. London: London, UK, 312320.

Unity Technologies. Unity3D, 2005. https://unity3d.com (last accessed 24/01/2022).

Utsi, E.C., 2017. Ground Penetrating Radar: Theory and Practice, Butterworth-Heinemann: Oxford, UK.

Yoon, S.-E., Gobbetti, E., Kasik, D., Manocha, D., 2008. RealTime Massive Model Rendering, vol. 2. 07. doi:10.2200/ S00131ED1V01Y200807CGR007. 2. 